\title{
Foucault como kantiano: acerca de um pensamento do homem desde sua própria finitude
}

\author{
Foucault regarded as a kantian: the thought of man based on his \\ own finiteness
}

\section{Daniel Omar Perez}

Doutor em Filosofia, Universidade Estadual de Campinas (Unicamp), professor titular da Pontifícia Universidade Católica do Paraná (PUCPR), Curitiba, PR - Brasil, e-mail: danielomarperez@hotmail.com

\section{Resumo}

Eu irei me limitar à leitura cuidadosa e austera da monografia sobre a Antropologia pragmática de Kant, de autoria de M. Foucault. Minha intenção é empreender um trabalho de crítica no interior dos estudos kantianos, diante dos quais tratarei Foucault como kantiano, como estudioso de Kant, como um acadêmico que procura apresentar uma exegese interpretativa do texto kantiano e pretende, com isso, a legitimidade do seu trabalho. Isto irá me permitir avaliar a interpretação foucaultiana de Kant com o intuito de reconsiderar o lugar e o alcance da Antropologia Pragmática na constituição da figura do homem como objeto das ciências.

Palavras-chave: Foucault. Kant. Antropologia. Ser humano. Finitude. 


\section{Abstract}

I am going to limit myself to the careful and austere reading of $M$. Foucault's monograph about Kant's Pragmatic Anthropology. My intent is engaging myself in a task of criticism about the Katian studies, based on which I will consider Foucault as a kantian - a scholar of Kant - and as an academician who tries to present an interpretive exegesis of the kantian texts and wants to achieve legitimacy from his writings. This shall allow me to assess the foucaultian interpretation of Kant, with the aim of reconsidering the place and reach of Pragmatic Anthropology in the constitution of man, as object of sciences.

Keywords: Foucault. Kant. Anthropology. Human Being. Finiteness.

\section{Introdução}

Após 1958, com a versão quase acabada da sua tese, Michel Foucault (32 anos de idade) preparou seu trabalho complementário (a maior parte da tarefa realizada na cidade de Hamburg) sob o título Gênese e estrutura da antropologia de Kant. O título tem uma referência clara à obra de Hyppolite, Gênese e estrutura da Fenomenologia do espírito.

Como sabemos, Foucault dedicou seu trabalho de conclusão de curso de licenciatura à obra de Hegel e, certamente, o texto mencionado foi leitura obrigatória. No entanto, sua tese de doutorado, História da loucura, tem a marca de um empreendimento diferente. Não se nota nada parecido com um hegelianismo e nem mesmo com algo como a continuação do trabalho anterior. Também pode se verificar só quatro referências a Kant, sendo apenas uma delas da Antropologia em sentido pragmático.

A passagem do estudo de Hegel - na graduação - para Kant - no anexo do doutorado e a elaboração de uma pesquisa sobre a loucura como trabalho de doutorado no meio das duas pesquisas anteriores - revela uma aparente desconexão entre os diferentes textos. Porém, na formação intelectual de Foucault, a obra de Kant está vinculada com a de Heidegger, o qual baliza o seu início fortemente e de modo bastante explícito. Castro $(2009$, p. 10) afirma que a leitura heideggeriana está presente na abordagem de Foucault sobre Kant e seus indícios podem ser documentados biograficamente. Durante seus anos de estudante na École Normale, Foucault 
acompanhou o curso de Jean Beaufret sobre a Crítica da Faculdade de Julgar. Beaufret foi um importante interlocutor de Heidegger depois da Segunda Guerra Mundial e analisante de Lacan. Podemos dizer que Beaufret reapresentou Heidegger não só ao Foucault, mas à sociedade filosófica e psicanalítica parisiense depois do processo de desnazificação com a Carta sobre o humanismo e com a releitura de antigos textos.

Beaufret usava com frequência o texto de Heidegger, Kant e o problema da metafísica, como referência de leitura em seu curso. Esse escrito heideggeriano destaca os elementos antropológicos da primeira crítica kantiana. A tese de Heidegger sobre Kant é a seguinte (HEIDEGGER, 1986, p. 11):

Esta investigação se propõe a tarefa de interpretar a Crítica da razão pura de Kant como uma fundamentação da metafísica. O problema fundamental da metafísica se coloca, pois, como o problema de uma ontologia fundamental. Chama-se ontologia fundamental à analítica ontológica da essência finita do homem que deve preparar o fundamento de uma metafísica conforme a natureza do homem.

Com efeito, de acordo com Heidegger, trata-se de mostrar na Crítica a "originareidade da origem da metafísica" como "pertencente à natureza do homem” (HEIDEGGER, 1986, p. 12). Heidegger avança em seu trabalho e no parágrafo 36 chega às seguintes considerações:

O que acontece na fundamentação kantiana? Nada menos que o seguinte: funda-se na possibilidade interna da ontologia como revelação da transcendência, quer dizer, da subjetividade do sujeito. A pergunta pela essência da metafísica é a pergunta pelas faculdades do "espírito" humano. A fundamentação kantiana revela o seguinte: fundar a metafísica é igual a perguntar pelo homem, quer dizer, antropologia. (HEIDEGGER, 1986, p. 174)

O trabalho crítico de Kant, segundo Heidegger, leva à pergunta pelo homem na forma de uma indagação antropológica e é nesse ponto onde ancora toda a sua reflexão. Na mesma direção, há outro texto importante de Heidegger que teria sido uma referência de Foucault: A época da imagem do mundo. Neste texto, Heidegger (1980, p. 73-110) afirma: 
Contudo, se o homem se transforma no sujeito primeiro e em sentido mais próprio, isto significa que o homem se transforma no ente sobre o qual se funda todo o ente no seu modo de ser e na sua verdade. O homem se transforma no centro de referência do ente enquanto tal. Mas isto também só é possível se a acepção do ente em sua totalidade também muda.

Castro acrescenta (2009, p. 11):

[...] a tese central de Foucault, segundo a qual a modernidade e, portanto, o kantismo, é a época na qual o pensamento pensa a finitude desde a finitude ecoa as expressões do Heidegger daquele texto. Heidegger sustenta que na modernidade o homem pensa tudo o que existe a partir dele e na sua direção.

De fato, este é declaradamente o empreendimento kantiano na Crítica da faculdade de julgar, mais especificamente na teleologia, onde o homem é considerado um fim porque ele pode dar fins a si mesmo. Pensa-se em fins do mundo a partir dos fins do homem e do homem como fim. Cito Kant (AA $05 \mathrm{KU}$, parágrafo 82): "Ele [O homem] é o fim último aqui na Terra, porque é o único ser nela que pode se fazer um conceito dos fins por meio da sua razão, um sistema de fins". Kant seria assim o pensador que está no olho da questão fundamental na virada do século XVIII para o XIX. Assim, compreende-se a afirmação de Foucault, de 1966, em As palavras e as coisas. Uma arqueologia das ciências humanas (FOUCAULT, 1988), segundo a qual as condições de possibilidade da aparição do homem aconteceram no fim do século XVIII.

O fim do século XVIII é o momento no qual Kant reflete em sala de aula sobre a pergunta o que é o homem? Ao pensar a finitude a partir dela mesma, o homem é, por sua vez, objeto e sujeito, como aparece explicitamente em Antropologia desde um ponto de vista pragmático: não se trata apenas de saber o que a natureza fez do homem, mas do que o homem faz, deve e pode fazer de si mesmo. De acordo com os resultados de As palavras e as coisas, na passagem do século XVIII para o XIX, teria aparecido em concomitância entre a Filosofia e a formação da Biologia, a Economia política e a Filologia, uma analítica da finitude. Cito Foucault (1988, p. 303-304): 
Quando a História Natural se transforma em Biologia, quando a análise da riqueza se transforma em economia, quando, fundamentalmente, a reflexão sobre a linguagem se faz Filologia e se apaga esse discurso clássico no qual o ser e a representação encontravam seu lugar comum, então no movimento profundo de tal mutação arqueológica aparece o homem e sua posição ambígua de objeto de um saber e sujeito que conhece [...].

Neste momento, surge a figura do homem. Esta é sua origem. De acordo com Foucault, origem aqui não seria um começo longínquo, senão que estaria presente no imediato do trabalho, a vida e a linguagem (FOUCAULT, 1988, p. 343-344). Com a emergência desta figura as ciências humanas (Psicologia, Sociologia, Teoria da Literatura e do Mito) teriam duplicado as ciências das quais teriam recebido seus modelos constitutivos. Da Biologia, as ciências humanas teriam herdado as noções de função e norma; da Economia Política, as noções de conflito e regra; e da Filologia as noções de significação e sistema.

Foucault se encarrega de mostrar que o homem, tal como o conhecemos desde as ciências humanas e sociais, não existia antes das configurações do pensamento do fim do século XVIII e de como sua figura está prestes a desaparecer graças à mudança dessas mesmas configurações. Na expressão escatológica da "morte do homem", trata-se menos da desaparição das pessoas do que de, obviamente, o desaparecimento da figura do homem e da emergência das estruturas.

Para esclarecer esse evento de transformação e passagem, podemos indicar dois elementos importantes. Por um lado, em entrevista de 1965, com Alan Badiou, Foucault declarava que o texto kantiano é o primeiro a colocar o problema do homem desde sua finitude. Todos os tratados anteriores teriam partido desde a infinitude de Deus para logo se interrogar pelo humano como criatura. Por outro lado, em outra entrevista de 1968, Foucault afirma que, quando se analisa a linguagem do homem, se descobrem as estruturas inconscientes que o governam, as estruturas que decidem o quadro dentro do qual falamos; que, quando um psicanalista analisa o comportamento ou a consciência de um indivíduo, não encontra o homem, mas a pulsão ou o instinto ou impulso, descobre-se o mecanismo, a semântica ou a sintaxe desses impulsos (FOUCAULT, 1994, p. 659). 
Nesse cenário, o valor da Introdução à antropologia em sentido pragmático de Foucault está em apresentar a matéria constitutiva da antropologia kantiana da qual vemos surgir a figura do homem e da analítica da finitude. Podemos dizer, pelas próprias declarações de Foucault, que a tradução e o estudo da antropologia em sentido pragmático não são apenas um anexo ocasional, o trabalho se articula com o próprio projeto de uma investigação acerca das ciências do homem desde sua base de constituição. Sendo assim, passamos à leitura ${ }^{1}$ foucaultiana do texto kantiano.

\section{A leitura do texto de Foucault sobre a antropologia kantiana}

O texto da Introdução à antropologia em sentido pragmático foi dividido de modo pertinente pelos seus editores em: 1 . Gênese da antropologia; 2. Lugar da antropologia no pensamento kantiano; 3. Estrutura e especificidade da antropologia de Kant; 4. A projeção da antropologia de Kant na filosofia contemporânea; 5. A relação entre a antropologia kantiana e as antropologias contemporâneas de Kant. A divisão do texto proposta explicita a sequência do trabalho desenvolvido por Foucault de um modo esclarecedor.

A primeira parte (Gênese da antropologia) localiza a emergência ou aparecimento da antropologia no trabalho filosófico de Kant. As informações que ali constam são bastante pouco conhecidas na época da redação do texto. Desde o ponto de vista de um estudo da história da filosofia, esta parte é de grande valor. Foucault menciona o curso de Geografia Física que Kant ministrava desde 1756 e o início do curso de Antropologia de 1772-1973. Menciona também os materiais com os quais deveria se trabalhar a Antropologia pragmática, a saber: as reflexões de Antropologia, os cursos, os textos publicados e os textos contemporâneos sob o domínio antropológico. Mas há uma declaração de Foucault, na forma de pergunta, que sugere o viés de leitura que marcará seu trabalho e o que nos interessa discutir aqui. Escreve Foucault:

1 Chamo de "leitura” ao modo de estabelecer uma hipótese de interpretação, citar um texto para reconstruir e argumentar com o intuito de provar o ponto de partida. 
Havia já desde 1772, e subsistindo talvez no fundo da Crítica, uma certa imagem concreta do homem que nenhuma elaboração filosófica alterou no essencial e que se formula finalmente sem maiores modificações no último dos textos publicados por Kant? E se essa imagem do homem recolheu a experiência crítica, sem, no entanto se desfigurar, não é talvez porque até certo ponto se não a organizou e dirigiu, pelo menos a tem guiado e orientado secretamente? (FOUCAULT, 2009, p. 41)

Foucault se pergunta se a imagem do homem acaso não está pressuposta no empreendimento kantiano desde antes da elaboração da própria crítica. Caso seja assim, a própria crítica da razão pura estaria desenhada sob o pano de fundo de uma figura humana preestabelecida. A afirmação dessa ideia seria problemática. Porém, antes de tirar qualquer conclusão, continuemos a citação foucaultiana:

Da crítica à antropologia haveria uma espécie de obscura e obstinada relação de finalidade. Entretanto, pode ser também que a Antropologia tenha sido modificada nos seus elementos maiores na medida em que se desenvolvia a tentativa crítica (FOUCAULT, 2009, p. 41).

Por um lado, Foucault afirma uma relação entre crítica e antropologia, que não é obvia e precisa ser demonstrada, porém é extremamente sugestiva no momento do entendimento do trabalho antropológico de Kant, e não como apenas um mero agregado. Ele desenvolverá seus argumentos no decorrer do trabalho, mas é importante que essa afirmação seja destacada como ponto de partida porque é desde essa questão que se dividem as diferentes possíveis interpretações ${ }^{2}$. Por outro lado, Foucault não tinha elementos definitivos para decidir sobre a possibilidade ou não da Antropologia ter-se modificado no decorrer dos anos em que Kant ministrou o curso, mas de fato foi o que aconteceu. Tinha apenas como fontes de consulta Kants Menschenkunde oder philosophische Anthropologie, publicado em 1831, algumas referências indiretas e os resumos dos cursos publicados em 1915 no volume XV

2 Os estudos kantianos se dividem em diferentes linhas de interpretação sobre esse ponto. Muitos estudiosos não aceitam a possibilidade de integrar a Antropologia à filosofia crítica de Kant. 0 mais significativo deles é Brandt na Introdução ao volume XXV da Kants Gesammelteschriften. Outros como LOUDEN, R. Kant's impure ethics. New York: Oxford University Press, 2000. incluem a Antropologia como a parte impura da ética kantiana. 
das obras de Kant. Os outros manuscritos de aulas dos alunos de Kant só foram estabelecidos em 1997 no volume XXV da obra completa por Brandt e Stark. Nessa obra, podemos percorrer as nuances das mudanças e as reformulações feitas por Kant durante os 24 anos de aulas e, concomitantemente, do desenvolvimento da Filosofia crítica. Tanto o desenvolvimento dos conhecimentos pragmáticos da Antropologia quanto a Filosofia crítica foram projetos em andamento. Isto traz um problema para a resposta da questão em relação à Antropologia - crítica: nenhuma das duas questões é estática. O que significa que o modo como os cursos de Antropologia se iniciam tem uma relação bem diferente com as pesquisas da primeira crítica do que que tem na década de 1780 e 1790. Isto Foucault intui. Continuo com a citação:

A arqueologia do texto, se fosse possível, não permitiria ver nascer um homo criticus cuja estrutura diferiria no essencial do homem que o tem precedido? Quer dizer, a Crítica, em seu carácter de "propedêutica" da Filosofia, acrescentaria uma função constitutiva no nascimento e no devir das formas concretas da existência humana. Haveria certa verdade crítica do homem, filha da crítica das condições de verdade (FOUCAULT, 2009, p. 41).

Assim, chegamos à questão posta como sendo a relação de fundamentação ou de primazia lógica entre a figura do homem que se deriva da Antropologia e o desenvolvimento da Filosofia crítica de Kant. Trata-se de saber se a figura do homem precede ao trabalho crítico ou é este que conforma o nascimento daquela nova figura. Este é o ponto decisivo para pensar a virada do século XVIII para o XIX no que se refere ao papel da reflexão kantiana na constituição da figura do homem.

Se Kant partiu da figura do homem para ir ao trabalho crítico sobre a pergunta pelas condições de possibilidade das proposições sintéticas, então não fez mais que o que ele mesmo criticava, quer dizer, afirmou um dado empírico como princípio metafísico e a partir dele construiu uma teoria do juízo. Porém, se partiu desde a crítica e da interrogação pelas condições de possibilidade das proposições e dessas mesmas condições, avançou sobre a pergunta pelo homem, então estamos diante, já não da fundamentação metafísica do homem e sim da 
constituição-descobrimento da figura do homem que se corresponde com as formas da experiência cognitiva, prática e estética que emergem no uso da razão. Dito resumidamente no primeiro caso, tem-se uma afirmação metafísica arbitrária; no segundo caso, tem-se a constituição das subjetividades a partir de campos semânticos. Isto é tudo o que precisamos decidir.

A segunda parte do trabalho de Foucault (Lugar da antropologia no pensamento kantiano) estuda a relação da Antropologia com os textos pré-críticos, com os textos da maturidade de Kant e, finalmente, com a primeira crítica. Do ponto de vista analítico, este é o momento mais rico do trabalho. Do ponto de vista argumentativo, além de ser o mais rico, é também o momento mais ambíguo, porque Foucault parece navegar orçando entre privilegiar a crítica ou a Antropologia como ponto de fundamentação para, finalmente, se decidir pela segunda.

Para observar esse fenômeno, vamos pontuar alguns fragmentos do trabalho. Foucault mostra como a temática da Antropologia está presente nos textos pré-críticos, porém de um modo diferente do que se apresenta no texto da Antropologia. De acordo com as afirmações de Foucault, Kant teria ligado inicialmente a "Antropologia à Geografia Física" que, mais tarde, se consolidaria sob a perspectiva de um "conhecimento cosmopolita", vinculando-se com as discussões sobre o sujeito de direito e o sujeito moral e da história. Desse modo, Foucault observa como "o homem na Antropologia não é nem homo natura nem puro sujeito de liberdade, senão que é abordado nas sínteses já operadas da sua relação com o mundo" (FOUCAULT, 2009, p. 71). Por um lado, a Antropologia kantiana se apoia no Gemüt presente na estrutura das três críticas, por outro lado, destaca-se a observação e a experiência. "Assim, a Antropologia estaria entre o universal a priori e o temporal da experiência”. Mas não só isso, também estaria entre a crítica (o trabalho das três criticas publicadas por Kant) e a filosofia transcendental (não publicada por Kant, mas conhecida como Opus Postumun). Tratar-se-ia de uma interrogação do originário do homem a partir da relação entre a universalidade e a temporalidade. Essa é a parte decisiva da interpretação foucaultiana sobre Kant. Mas para afirmar isso talvez o ponto fundamental da leitura de Foucault tenha menos ênfase em 
Antropologia e mais em Opus Postumun, porque é desde lá que Foucault lê em Kant o conceito de homem.

Retomemos os termos. No seu trabalho de interpretação, Foucault destaca a passagem da Geografia para a Antropologia e do conhecimento natural e classificatório dos primeiros escritos sobre questões antropológicas para o conhecimento "de "mundo" como conhecimento cosmopolita. Mas adverte que não se trata de mera descrição de observação e experiência: "A ideia cosmopolita tem um valor programático na qual o mundo aparece mais como uma cidade a ser construída do que com um cosmos já dado" (FOUCAULT, 2009, p. 52). Com efeito, não é de uma mera descrição, mas de um conhecimento pragmático que Kant está cuidando na Antropologia. Trata-se de dois diferentes modos de abordar o ser humano, por um lado, como objeto de classificação (como, por exemplo, a das doenças mentais ou das raças) e, por outro lado, como "cidadão do mundo". De fato, a Antropologia abre com a proposição "o homem é cidadão do mundo" e não um mero objeto da natureza como poderia ser na história natural de Linneu.

Para mostrar as diferentes nuances das perspectivas de abordagem, Foucault (2009, p. 54) evoca uma série de cartas de Beck, redigidas entre 1794-1797, em que se colocam para Kant um número importante de questões sobre o trabalho da crítica em estreita relação com o problema do sujeito, a saber: a unidade sintética da consciência, a irredutibilidade da sensibilidade e do entendimento, a ligação originária entre o teórico e o prático. De acordo com Foucault, a resposta a todas essas questões estaria no texto da Antropologia em sentido pragmático e em um manuscrito deixado de lado na edição (FOUCAULT, 2009, p. 54-57).

Para justificar essa interpretação, há um fragmento de Foucault que deve ser destacado. Ele encontra uma nova distinção na Antropologia em sentido pragmático no que diz respeito a sentido interno e apercepção:

A apercepção que a Crítica reduzia ao simples eu penso se assemelha agora à atividade originária do sujeito, enquanto o sentido interno que na Crítica se analisava com a forma a priori do tempo é dada aqui dentro de um 'jogo do pensamento` que se joga por força da matriz mesma do sujeito e que faz do sentido interno o signo mais da passividade primeira do que de uma atividade constitutiva (FOUCAULT, 2009, p. 56). 
O que é interpretado como uma mudança de Kant (nas declarações de FOUCAULT, 2009, p. 56-57) poderia ser concebido também ou contrariamente como uma diferença de perspectiva. Explico: enquanto, na Crítica, o problema poderia ser abordado desde o ponto de vista lógico, na Antropologia a questão seria pensar esses elementos desde os requisitos antropológicos dos resultados da crítica. Mas Foucault não faz esse caminho. Isto permite pensar que sua escolha interpretativa já está decidida e que pressupõe que em Kant haveria uma concepção determinada da natureza humana a partir da qual surgem as operações que executam o poder judicativo. O que estou afirmando aqui precisa ainda ser demonstrado, mas antes darei algumas indicações resgatando fragmentos que pareceriam ir no sentido contrário. A Antropologia em sentido pragmático parece ter, para Foucault, um elemento decisivo que muda e supera as posições da crítica. O espaço no qual se definiria uma Antropologia em geral seria o de "região na qual a observação de si não tem acesso nem a um sujeito em si nem ao puro sujeito da síntese, mas a um eu que é objeto e presente unicamente na mera verdade fenomênica" (FOUCAULT, 2009, p. 57). O domínio da Antropologia em sentido pragmático seria aquele da unidade concreta da síntese e da passividade, do afetado e do constituído que se dá como fenômeno na forma do tempo. Análise das formas concretas da observação de si (FOUCAULT, 2009, p. 57). As observações de Foucault parecem indicar o contrário de uma natureza humana pressuposta. Mas avancemos mais na leitura para verificar como se desenvolve a posição de Foucault.

Os temas sobre a mulher, o matrimônio e a cidadania do mundo, bem como os problemas sobre hipocondria, dietética e impulso vital que perpassam a Antropologia em sentido pragmático, o Conflito das faculdades e as discussões nas correspondências com Schütz e Hufeland, apontam para a articulação de uma análise do homo natura com uma definição do homem como sujeito da liberdade (FOUCAULT, 2009, p. 66). As antigas discussões sobre a relação mente-corpo ou espírito e matéria são trabalhadas agora antropologicamente na articulação do estudo do homem como coisa natural e como ser moral (FOUCAULT, 2009, p. 67). Nesse sentido, toda essa parte da análise foucaultiana parece resgatar 
a autonomia do conhecimento pragmático, independentemente de ser ou não a Antropologia uma espécie de discurso fundador de uma figura de homem a partir da qual será elaborado o trabalho crítico. Essas variações de Foucault são possíveis porque se constatam, em certo sentido, na leitura da Antropologia em sentido pragmático, mas também de algum modo, porque ele já tem presente o que considera a conclusão do empreendimento kantiano dado no Opus Postumun, a saber, a relação entre Deus, o homem e o mundo. Expliquemos o que isto significa.

As diferentes afirmações conclusivas de Foucault se conduzem finalmente para chegar ao pressuposto de que a Antropologia em sentido pragmático é um trabalho na dupla relação com a Crítica e com Opus Postumun. Assim sendo, a primeira pergunta é: qual é a relação entre o conhecimento antropológico e a reflexão das críticas? Sendo a Antropologia em sentido pragmático pautada pelo resultado da divisão de faculdades elaborada na crítica, a segunda pergunta é: Em que se diferencia o estudo do Gemüt na Antropologia de um estudo de Psicologia seja ela empírica ou racional?

Para responder a tal questão, Foucault avança na impossibilidade de uma psicologia em Kant³: Gemüt não é Seele afirma Foucault (2009, p. 75) e procede a uma análise dos conceitos junto a Geist, Kraft, Vermögen, belebende Prinzip (princípio vivificante), durch Ideen (por meio de ideias). Disso retira algumas consequências: A Antropologia surge sobre a base do Gemüt ${ }^{4}$, mas com a vivificação do Geist. Cito Foucault (2009, p. 78):

A presença do Geist e com ele essa dimensão da liberdade e da totalidade que transcende o Gemüt faz com que não tenhamos outra verdadeira antropologia senão a pragmática, sendo cada fato abordado dentro do sistema aberto do Könen e do Sollen.

Segundo Foucault, a abordagem da questão antropológica pela via da vivificação do Geist presente no Gemüt demonstraria o desnecessário de uma antropologia fisiológica. Eu não seria tão corajoso quanto

3 Sobre a impossibilidade da Psicologia como ciência em Kant ver PEREZ, D. O. A loucura como questão semântica: uma interpretação kantiana. Revista Trasformação, Marilia, v. 32, p. 95-117, 2009a.

4 Sobre a significação de Gemüt em Kant ROHDEN, V. 0 sentido do termo Gemüt em Kant. In: PEREZ, D.O. Kant no Brasil. São Paulo: Escuta, 2005. p. 25-40.. 
Foucault ao ponto de afirmar que é por isso que Kant não escreveu uma antropologia desse tipo. Certamente, de fato Kant não escreveu um trabalho à parte, mas a Fisiologia humana está permanente presente não só na Antropologia em sentido pragmático, mas também no Conflito das Faculdades, e outros textos sobre história. Só para dar um exemplo, na Característica da Antropologia em sentido pragmático Kant afirma que o ser humano tem dois instintos (impulsos, trieben) básicos: a sexualidade e a liberdade. A sexualidade, o apetite sexual, o impulso para copular é o que conduz o ser humano à sociabilidade. Outro exemplo é a forma da mão, a posição dos dedos da mão está na base das suas capacidades técnicas. Portanto, Kant não escreveu uma antropologia fisiológica à parte, mas os elementos da natureza (fisiológica e orgânica) humana estão no texto tudo e se articulam na vivificação do Geist.

Voltando ao texto de Foucault, afirma-se que a Antropologia seria o negativo da crítica (FOUCAULT, 2009, p. 80). No meu entendimento, o negativo no sentido de uma foto com filme a ser revelado, não no sentido do contrário. Para ilustrar, Foucault destaca que, na Antropologia em sentido pragmático, o Eu é objeto, na crítica não pode ser objeto. Cito Foucault (2009, p. 81-82):

Por outras palavras, aquilo que desde o ponto de vista da Crítica é o $a$ priori do conhecimento não se coloca imediatamente na reflexão antropológica como o a priori da existência, senão que aparece dentro do âmbito de um devir no qual sua súbita emergência infalivelmente adquire na retrospecção o sentido do já-alí. [...] o estatuto do a priori na ordem do conhecimento crítico passa para uma aparição de um originário na Antropologia.

Mais ainda, de acordo com Foucault, a Antropologia em sentido pragmático se baseia na divisão das faculdades, mas diferentemente da crítica, ao contrário de descrever seus poderes privilegia suas fraquezas, os perigos nos quais pode se perder (FOUCAULT, 2009, p. 82). Com efeito, Kant está relevando o conhecimento daquilo que pode propiciar ou obstaculizar o exercício da liberdade e, portanto, da razão prática. Isto, que Foucault parece interpretar como um avanço, ou até mesmo uma superação, do tratamento da crítica pode também ser 
interpretado como uma extensão de um domínio da razão segundo foi estabelecida na segunda crítica. A Antropologia parte dos resultados da filosofia e a partir daí ordena seus conhecimentos de modo sistemático (AA 07 Anth, 22). É claro que os resultados da filosofia aos quais se refere Kant são os que se desenvolvem a partir da pergunta pela possibilidade das proposições sintéticas e estão em construção durante todo o período de elaboração dos cursos de antropologia. Porém Foucault não considera essa possiblidade porque já decidiu qual é o lugar da Antropologia em sentido pragmático antes mesmo de proceder à análise. Para reforçar essa interpretação - como sendo a Antropologia um passo para além das críticas - ele apela para uma analogia entre as divisões dos textos das críticas com a Antropologia em sentido pragmático. Foucault chama a atenção para a divisão da crítica em Elementarlehre e Methodenlehre, que se difere em Antropologia em sentido pragmático com didática e característica considerando a segunda divisão como um descobrimento da última etapa da reflexão kantiana, de onde tira algumas conclusões (FOUCAULT, 2009, p. 84-86). Isso é incorreto, essa divisão da Antropologia é tão antiga quanto à das críticas, mas Foucault não tinha como saber disso a não ser que consultasse os manuscritos dos cursos ministrados até 1780 somente publicados em 1997.

Porém, há algo que Foucault, sim, poderia ter tido notícia e, acredito, esse dado teria colocado problemas para a argumentação dessa interpretação. No entanto, antes de apresentá-lo, vejamos o texto onde Foucault (2009, p. 88-89) afirma que:

[...] a Antropologia tal como a conhecemos não se concebe em momento nenhum como a resposta à quarta pergunta, nem se quer como o aproveitamento empírico mais amplo dessa pergunta, senão que esta só é colocada mais tarde, fora da Antropologia e em uma perspectiva que não lhe pertence de maneira característica, no momento em que se totaliza no pensamento kantiano o Philosophieren, quer dizer, na Lógica e no Opus Postumun.

Podemos concordar com a primeira parte da afirmação: a Antropologia em sentido pragmático não responde à quarta pergunta diretamente (o que abriria a possibilidade de uma resposta indireta, inacabada), 
mas dessa afirmação não se deriva a segunda parte do enunciado. Pior ainda, é na carta a C.F. Stäudlin, de 1793, que Kant descreve o plano do seu sistema de filosofia pura e acrescenta a quarta pergunta: que éo ser humano? Afirma ele que essa questão pertence à Antropologia, tema sobre o qual tem lecionado por mais de 20 anos (AA 11; 429). Cito Kant para não haver dúvidas com qualquer tergiversação:

Mein schon seit geraumer Zeit gemachter Plan der mir obliegenden Bearbeitung des Feldes der reinen Philosophie ging auf die auflösung der drei Aufgaben: 1. Was kann ich wissen? (Metaphysik); 2. Was soll ich thun? (Moral); 3. Was darf ich hoffen (Religion); welcher zuletzt die vierte folgen sollte: Was ist der Mensch? (Anthropologie, über die ich schon seit mehr als 20 Jahren jährlech ein Collegium gelesen habe).

Esta afirmação deve, senão ser integrada, pelo menos ser articulada de alguma forma na interpretação. Mas Foucault não faz isso. Apenas cita a questão da quarta pergunta desde a declaração ambígua encontrada no texto da Lógica e para dar um sentido determinado vai orientar sua interpretação para o Opus Postumun, em que a filosofia transcendental é dividida em três secções: Deus, o mundo e o eu mesmo do homem como ser moral (FOUCAULT, 2009, p. 89). Foucault afirma, seguindo Kant, que o terceiro elemento não é complemento senão "medius terminus" "é a unidade concreta e ativa na qual e pela qual Deus e o mundo encontram sua unidade” (FOUCAULT, 2009, p. 89). A pergunta óbvia é: em que medida o homem ocupa esse lugar? Resposta: "Se o homem dá unidade ao mundo e a Deus, é na medida em que exerce sua soberania de sujeito pensante, que pensa Deus e o mundo" (FOUCAULT, 2009, p. 89). Esse ato seria, segundo a interpretação foucaultiana, a mesma síntese do pensamento. A relação comporia a estrutura mesma do juízo, sujeito - cópula-predicado, onde a cópula é (ser)? é o homem. O homem apareceria como a síntese universal na qual se reúne a personalidade de Deus e a objetividade do mundo: só a partir do homem pode se pensar o absoluto (FOUCAULT, 2009, p. 90). Essa interpretação não resiste à leitura do texto da Antropologia, onde não encontramos qualquer indício de síntese na figura do homem senão apenas a sistematização de conhecimentos pragmáticos. O próprio 
Foucault escreve: "Na região antropológica, não há nenhuma síntese que não esteja ameaçada: o domínio da experiência está como socavado desde o interior por perigos que não são da ordem da superação arbitrária, senão do derrubamento sobre si" (FOUCAULT, 2009, p. 83). Para introduzir sua noção de "síntese", Foucault deve sair da Antropologia e recorrer aos manuscritos kantianos escritos entre 1800 e 1803 e publicados postumamente pelos herdeiros de Kant. Porém, Foucault considera o Opus Postumun como um texto onde, finalmente, "uma filosofia transcendental foi alcançada" (FOUCAULT, 2009, p. 91) e o homem seria a síntese última e fundadora da relação Deus e o mundo, coisa que é muito difícil de sustentar para além da interpretação sobre alguns dos fragmentos de Opus Postumun. Entre outras coisas, isto é por algo que o próprio Foucault nota: "o homem se define como habitante do mundo [...] E toda reflexão sobre o homem é remitida circularmente a uma reflexão sobre o mundo" (FOUCAULT, 2009, p. 91). Entretanto, é fácil chegar à conclusão de "homem como síntese" pela via da leitura de Heidegger que Foucault tão bem estudou naquela época.

Foucault considera que a Antropologia retoma o que está na Crítica e avança na noção de homem cosmopolita, mas a articula com o Opus Postumun (como filosofia transcendental) introduzindo a ideia de Deus. Assim, Foucault expõe a noção kantiana de mundo em Opus Postumun (como fonte de saber, domínio dos predicados possíveis e limite da experiência possível) e de Deus. Foucault faz a correlação desses conceitos com a razão pura, a prática e a faculdade de julgar. Assim sendo, sobre essa base repousariam as três perguntas kantianas. Com relação à quarta pergunta, avança Foucault:

A pergunta antropológica não tem conteúdo independente, explicitado, ela repete as três perguntas, porém as repete substituindo uma tripartição mais ou menos diretamente tomada da distinção das faculdades pelo jogo de três noções que cobrem as relações do homem com o mundo: não relações empíricas e circulares das imanências no nível de um conhecimento natural, senão correlação necessária, quer dizer, originária, na que se desenvolvem desde a raiz da existência das coisas, de inseparáveis transcendências (FOUCAULT, 2009, p. 98). 
A pergunta: o que é o homem? teria como sentido e função levar a divisão das críticas ao grau de uma coesão fundamental. Essa coesão fundamental estaria desenhada numa estrutura "liberada de uma filosofia transcendental" (FOUCAULT, 2009, p. 98). Pode-se deduzir que essa liberação consistiria em deixar de tratar o tema do homem em termos a priori para colocá-lo na temporalidade do mundo. Mas isso seria correto se Kant tivesse tratado o homem na crítica e não as condições de possibilidade das proposições (ou juízos) sintéticos ${ }^{5}$. Como podemos observar, Foucault chega a essa conclusão porque efetivamente parte da premissa de que uma determinada concepção de homem precede o trabalho da crítica.

Teríamos, nesse ponto, um mero problema interpretativo se a mudança de interpretação não alterasse também o estatuto da própria questão que Foucault tem como propósito discutir, a saber: o aparecimento da figura do homem e de uma analítica da finitude que permita compreender a passagem do século XVIII para o século XIX, no que se refere à passagem da história natural, as reflexões sobre a linguagem e a análise das riquezas para o aparecimento das ciências humanas e sociais. Colocar a antropologia kantiana como fundamental em relação com a crítica não nos permitiria ver como Kant parte da análise da linguagem nas suas estruturas proposicionais (sujeito-predicado) que fazem sentido em campos semânticos (cognitivos, práticos, reflexivos), instaurando assim a possibilidade dos espaços dos sujeitos de experiências cognitivas, morais, estéticas, etc.; e de como isso se relaciona com um ser racional finito que, na sua especificidade, só pode ser conhecido pragmaticamente.

A terceira parte do trabalho de Foucault (Estrutura e especificidade da Antropologia de Kant) começa procurando estabelecer o lugar da Antropologia entre a Crítica e Opus Postumum. Por um lado, nesse horizonte nos adverte que "a crítica não tem o valor de fundamento com relação à Antropologia. Esta repousa em seu trabalho, mas não

5 Sobre um estudo acerca do trabalho da filosofia transcendental como 0 desenvolvimento da interrogação kantiana sobre as condições de possibilidade das proposições sintéticas ver PEREZ, D. 0. Kant e o problema da significação. Curitiba: Champagnat, 2008. 
se ancora nela" (FOUCAULT, 2009, p. 99). Aquilo que a funda seria "a filosofia transcendental". Note-se que a noção de uma filosofia transcendental já está definida na primeira crítica, mas Foucault prefere dissociá-las remetendo a segunda a uma interpretação da definição dada em alguns fragmentos de Opus Postumum. Prefere dar destaque à ideia de uma crítica como propedêutica e a uma filosofia transcendental como o sistema de Deus, o mundo e o eu. Por outro lado, na sua autonomia, a Antropologia é definida como sistemática e popular. De acordo com Foucault, sistemática não quer dizer que enuncie sobre o homem tudo aquilo que pode se conhecido (FOUCAULT, 2009, p. 99). Assim Foucault elucida:

Sistemática em virtude de uma estrutura que é a da Crítica, e que a repete. Porém, o que a Crítica enuncia como determinação, na relação entre a espontaneidade e a passividade, a Antropologia descreve na relação temporal, que não acaba jamais e jamais começou; aquilo de que se ocupa a Antropologia está sempre ali, e nunca é inteiramente dado; aquilo que é primeiro para ela está consagrado a um tempo que o envolve de todas as maneiras, desde longe e desde cima (FOUCAULT, 2009, p. 103).

Com efeito, segundo Foucault, trata-se de "recuperar uma trama temporal", o originário como temporal. Nesse sentido, "a verdade e a liberdade se correspondem” (FOUCAULT, 2009, p. 103).

Assim, o caráter popular da obra é referido por Foucault ao fio condutor empírico dos casos, à linguagem utilizada e ao estudo sobre esses exemplos e essas expressões da linguagem com os quais lida o homem no conhecimento do mundo. Sua análise sobre um trabalho popular em Filosofia e, especificamente, em Antropologia pragmática, é muito pertinente e é da qual Foucault faz uso para demonstrar que, por um lado a Antropologia é ciência autônoma e, por outro lado, é fundamento.

A quarta parte do trabalho de Foucault (A projeção da Antropologia de Kant na Filosofia contemporânea) nos dá uma declaração explícita da sua interpretação. Cito:

A Antropologia é, pois, na essência a investigação de um campo no qual o prático e o teórico se atravessam e se recobrem inteiramente; ela 
repete, no mesmo lugar e numa mesma linguagem, o a priori do conhecimento e o imperativo da moral - e desse modo, pelo movimento dessa palavra empírica que é a sua, conduz para aquilo que postula: uma filosofia transcendental na qual se encontra definida, desde seu fundamento mesmo, a relação entre a verdade e a liberdade (FOUCAULT, 2009, p. 113-114).

Foucault percebe que o conhecimento antropológico inclui questões do âmbito teórico e do âmbito prático, mas isso não o faz refletir sobre o caráter pragmático desse conhecimento. Como Foucault colocou a Antropologia num lugar de fundamentação em relação ao trabalho crítico, ele não reconhece a possibilidade de se interrogar pelo tipo de conhecimento que seria o pragmático. Kant divide todo o conhecimento em teórico ou prático. Cada tipo de proposição, que caracterizaria um determinado conhecimento, deve estar inserido ou no âmbito teórico (como é o caso das proposições da Geometria, Matemática ou Física) ou no âmbito prático (como é o caso das proposições do direito, da virtude ou da história). Se Kant está propondo uma antropologia sistemática e popular, como o próprio Foucault adverte, a pergunta deveria ser: que tipo de proposições sustenta esse conhecimento? Dentro de que âmbito esse conhecimento sistemático deve ser inserido para pertencer ao sistema? Mas, em vez de se conduzir por esse caminho, Foucault coloca o conhecimento da Antropologia num substrato anterior ao conhecimento da própria crítica. O conhecimento da crítica é um conhecimento transcendental, no sentido de nos fornecer as condições de possibilidade das proposições sintéticas. Um conhecimento anterior ao conhecimento das condições transcendentais de possibilidade já não seria possível de sustentar sem estar afirmando metafisicamente aquilo que não se pode provar. Isto nos leva a concluir mais uma vez que, se Kant tivesse colocado a Antropologia onde Foucault pretende, então teria feito aquilo que o próprio Kant pretende criticar, isto é, teria ido para além dos limites do uso da razão. Para evitar isso, poderíamos ensaiar a tentativa de compreender o conhecimento pragmático como inserido no domínio prático ${ }^{6}$.

6 Sobre esse tipo de interpretação ver PEREZ, D. 0. A antropologia pragmática como parte da razão prática em sentido kantiano. Manuscrito Revista Internacional de Filosofia, v. 32, n. 2 p. 357-397, 2009b. 
A quinta parte do trabalho de Foucault (A relação entre a antropologia kantiana e as antropologias contemporâneas de Kant) oferece dados históricos muito relevantes para compreender a problemática de uma antropologia na virada do século XVIII para o XIX. Menciona-se uma série de textos que faz referência explícita a Kant e outra série que teria influenciado o filósofo em seu trabalho. Deste segundo grupo, destacamos o livro de Baumgarten Psicologia empírica (1749), de Plätner Nova antropologia para médicos e sábios do mundo, com especial consideração da fisiologia, a filosofia moral e a estética (1772) e de Tetens Ensaio sobre a natureza humana (1777). O texto de Baumgarten serviu como fio condutor do curso de Kant, o de Plätner como contraponto e o de Tetens como material de consulta.

Foucault afirma que, na época, o estudo do homem era considerado de dois modos. Por um lado, desde o ponto de vista da Fisiologia, sendo esta a "ciência dos corpos animados" ou considerado como espécie, segundo Wolff (FOUCAULT, 2009, p. 122). Plätner arrisca uma definição da Antropologia como as relações, limitações e conexões entre o corpo e a alma (FOUCAULT, 2009, p. 122). Segundo Tetens, a Antropologia estudaria as modificações da alma, mas, pelo lado do cérebro, como o órgão interno daquela e se procura explicar como estados e modificações cerebrais (FOUCAULT, 2009, p. 123). Por outro lado, Schmid na sua Psicologia empírica (1791) afirma que os instrumentos do estudo empírico da alma são os "livros de histórias, biografias, observações sobre o caráter, poesia trágica e cômica, romance” (FOUCAULT, 2009, p. 120). Também Lacretelle em De l'établissement des connaissances humaines (1792) considera a Antropologia como o conjunto de conhecimentos do "homem considerado em relações pessoais e dos homens reunidos em associações políticas” (FOUCAULT, 2009, p. 124). O que induz Foucault a concluir:

[...] a Antropologia: é o conhecimento do homem, em um movimento que objetiva este, no nível do seu ser natural e no seu conteúdo de determinações animais; mas é conhecimento do conhecimento do homem, em um movimento que interroga o sujeito sobre ele mesmo, sobre seus limites e sobre aquilo que ele autoriza no saber que se tem dele (FOUCAULT, 2009, p. 125). 
O trabalho antropológico de Kant teria encontrado um lugar para o estudo do homo natura sem deixar de considerá-lo como habitando o mundo na medida em que é cidadão. Com isso, podemos dizer que Kant abriu a possibilidade de pensar o homem como objeto e sujeito: condição necessária para as ciências sociais e humanas de um tempo futuro.

\section{Considerações finais}

A tese de Foucault, fortemente influenciada pela posição heideggeriana em Kant e o problema da metafísica, sobre a relação do trabalho crítico com a Antropologia, lhe permite ver a importância de uma reflexão da finitude desde o finito e da possibilidade de uma analítica da finitude. Porém lhe oculta a possibilidade de reconhecer que essa analítica da finitude não parte de uma decisão metafísica de uma determinada concepção do homem e sim da análise das estruturas proposicionais. A mudança de interpretação lhe teria permitido reconhecer em Kant não apenas a possibilidade da analítica da finitude senão também a possibilidade do estruturalismo.

Foucault (2009, p. 127) escreve que, na Antropologia, a estrutura mesma do problema kantiano é "como pensar, analisar, justificar e fundar a finitude dentro de uma reflexão que não passa por uma ontologia do infinito e não se escusa numa filosofia do absoluto?" Com efeito, a isso poderíamos acrescentar que, na Crítica, a estrutura do problema kantiano é: como são possíveis os juízos sintéticos dentro de uma análise que não passa por uma explicação sensualista nem por um inatismo, mas que trata a questão em termos lógicos e referenciais? A partir da resposta é que podemos falar de sujeito de uma experiência cognitiva ou de uma experiência moral ou de uma experiência estética, etc. e nos conduzir à pergunta: o que é o homem?

A importância do trabalho e da interpretação do trabalho de Kant é que "a Filosofia não tem se libertado da subjetividade como tese fundamental e ponto de partida da sua reflexão" (FOUCAULT, 2009, p. 130). Poderíamos dizer que ainda vivemos sob sua sombra. Nesse sentido, Foucault (2009, p. 116) escreve: 
Qual será a cegueira da qual temos nos favorecido para não ver que a articulação autêntica do Philosophieren [filosofar] estava novamente presente, e sob uma forma muito mais urgente, em um pensamento que talvez não tinha advertido com exatidão, ele próprio, o que conservava de filiação e de fidelidade com relação ao velho "chinês de Königsberg".

Essa menção não é meramente a advertência de um descuido, é para Foucault uma tarefa que nos levaria da interrogação sobre o homem desde Kant à afirmação do Übermensch de Nietzsche: "A empresa nietzschiana poderia ser entendida como o ponto de cessação dado por fim a proliferação da interrogação sobre o homem" (FOUCAULT, 2009, p. 131). Para decidir sobre a pertinência dessa passagem, que não é senão uma posição filosófico-política, deveríamos antes avançar na análise de conceitos como analítica da finitude, história como analítica do presente, acontecimento histórico e entusiasmo pela revolução (todos eles tratados pelo próprio Foucault).

\section{Referências}

CASTRO, E. Foucault lector de Kant. In: FOUCAULT, M. Una lectura de Kant: introducción a la antropología en sentido pragmático. Buenos Aires: Siglo XXI, 2009. p. 9-29.

FOUCAULT, M. Una lectura de Kant: introducción a la antropología en sentido pragmático. Buenos Aires: Siglo XXI, 2009.

FOUCAULT, M. its et écrits. Paris: Gallimard, 1994. v. 1.

FOUCAULT, M. As palavras e as coisas: uma arqueologia das ciências humanas. México: FCE, 1988.

HEIDEGGER, M. Kant e o problema da metafísica. México: FCE, 1986.

HEIDEGGER, M. Die Zeit des Weltbildes. In: HEIDEGGER, M. Holzwege. 6. ed. Frankfurt: Vittorio Klostermann, 1980. p. 73-110.

KANT, I. Kant's gesammelte schriften. Berlin: Walter de Gruyter \& Co, 1902. 
LOUDEN, R. Kant's impure ethics. New York: Oxford University Press, 2000.

PEREZ, D. O. Kant e o problema da significação. Curitiba: Champagnat, 2008. PEREZ, D. O. A loucura como questão semântica: uma interpretação kantiana. Revista Trasformação, Marilia, v. 32, p. 95-117, 2009 a.

PEREZ, D. O. A Antropologia pragmática como parte da razão prática em sentido kantiano. Manuscrito Revista Internacional de Filosofia, v. 32, n. 2 p. 357-397, 2009b.

ROHDEN, V. O sentido do termo Gemüt em Kant. In: PEREZ, D. O. Kant no Brasil. São Paulo: Escuta, 2005. p. 25-40.

Recebido: 16/09/2011

Received: 09/16/2011

Aprovado: 30/01/2012

Approved: 01/30/2012 